\title{
Emergency Bilateral Internal Iliac Ligation for Managing Postpartum Hemorrhage as Life Saving Measure in Private Nursing Homes in Semi-urban Settings
}

\author{
${ }^{1}$ Abhay Shete, ${ }^{2}$ Meghana Kulkarni, ${ }^{3}$ Kalpana Shete, ${ }^{4}$ Kedar Walimbe, ${ }^{5}$ Firoz Mulla
}

\begin{abstract}
A study of 30 cases that underwent emergency bilateral internal iliac artery ligation (EBIIAL) from June 2006 to April 2013 at private nursing homes, which can be best described as secondary level healthcare units, was undertaken to assess the efficacy and the outcome of the procedure in managing labors complicated by postpartum hemorrhage (PPH). The obstetricians managing the cases preferred to preserve the uterus for menstrual and future child bearing option and deferred obstetric hysterectomy. The procedure of embolization of uterine artery is available at tertiary care setups which are about 20 to $50 \mathrm{~km}$ away from the place of delivery requiring transfer of the parturient increasing the burden on the family and relatives of the parturient. EBIIAL done at the place where the parturient delivers has helped in stemming the transfers and preserving the menstrual and fertility options. The early diagnosis and recognition of failure of the uterotonic agents to control PPH helps in identifying those cases that would benefit from EBIIAL. This helps in reducing the inadvertent blood loss that occurs during atonic PPH and also minimizing the requirement for blood transfusions. In our study three parturient had to be transferred following EBIIAL for management of early disseminated intravascular coagulation (DIC) and one for diagnosing of associated Berger's disease that was suspected after noticing temperature difference in the limbs following ligation of her iliac arteries.
\end{abstract}

Keywords: Uterine atony, PPH, DIC, Hypogastric artery ligation, EBIIAL, Arterial embolization.

How to cite this article: Shete A, Kulkarni M, Shete K, Walimbe K, Mulla F. Emergency Bilateral Internal Iliac Ligation for Managing Postpartum Hemorrhage as Life Saving Measure in Private Nursing Homes in Semi-urban Settings. J South Asian Feder Obst Gynae 2014;6(2):79-82.

\footnotetext{
${ }^{1-5}$ Consultant

1,2Department of Obstetrics and Gynecology, Ameya Clinic Mother and Child Care Clinic, Panvel, Maharashtra, India

${ }^{3}$ Department of Neonatology and Pediatrics, Ameya Clinic Mother and Child Care Clinic, Panvel Maharashtra, India

4,5 Department of Anesthesiology, Ameya Clinic, Mother and Child Care Clinic, Panvel, Maharashtra, India
}

Corresponding Author: Abhay Shete, Consultant, Department of Obstetrics and Gynecology, Ameya Clinic, Mother and Child Care Clinic, Panvel, Maharashtra, India, e-mail: imabhayone@ yahoo.com

\section{Source of support: Nil}

Conflict of interest: None declared

\section{INTRODUCTION}

The practice of obstetrics is by and large influenced by the economical, cultural and social structure surrounding the patient and the obstetrician. The parturient delivers at home, primary, secondary or tertiary healthcare setups each having their advantages and disadvantages. The tertiary care setups though ideally suited to deliver high-risk parturient, turn out to be inconvenient and expensive for those who are at low-risk or have no complications. However, complications can occur in seemingly normal parturient and it is here that emergency bilateral internal iliac artery ligation (EBIIAL) improves the services offered at primary and secondary level healthcare centers. The first internal iliac artery ligation (IIAL) reported in United States was performed by Howard and Kelly in $1894 .{ }^{1}$ Unilateral or bilateral hypogastric artery ligation can be life-saving in patients with massive postpartum hemorrhage (PPH). ${ }^{2,3}$ Uterine atony is the common cause of PPH that accounts for $80 \%$ of the cases. In low resource situations where advanced techniques to control hemorrhage are not available or unaffordable by the patients, bilateral internal iliac artery ligation is a better option for controlling obstetric hemorrhage. ${ }^{4}$ It has also been concluded that internal iliac arteries ligation is a prerequisite treatment of severe postpartum hemorrhage and it is a good alternative to arterial embolization. ${ }^{5}$ Some studies have concluded that those patients with high-risk for PPH must be transferred to appropriate centers to prevent a possible fatal outcome. ${ }^{6,7} \mathrm{In}$ a study similar to the study presented it was concluded that hypogatric artery ligation is an effective therapeutic option for severe PPH in a secondary care center. ${ }^{8}$

\section{MATERIALS AND METHODS}

We are team of obstetricians, neonatologist and anesthetists working in private nursing homes as opposed to the state run health centers and corporate hospitals catering to the semi-urban and rural population. We started propagating EBIIAL for PPH from 2006 onward and referred the parturient selectively for further care based on the prevailing condition of the patient. The patient was assessed for 
blood loss and the condition of her uterus and internal iliac arteries on either side were occluded with nonabsorbable suture material after identifying and separating them from the retroperitoneal adjoining veins. The intention was to treat $\mathrm{PPH}$ as aggressively as possible by early diagnosis of $\mathrm{PPH}$. The need to transfer the patient to higher centers was brought down only to those cases where there was need for further treatment as monitoring in intensive care units (ICU) or for aiding multidisciplinary approach to management of the patient. The patient was not shifted from the place where she delivered but was taken up for ligation of her internal iliac arteries at the same nursing home. Most of the times the patient was seen on the operation table where atonic PPH was diagnosed after the delivery of the baby by the obstetrician. At other times the patient was explored after the bleeding was found to be severe following vaginal birth or after the patient had been shifted to the ward post lower segment cesarean section (LSCS). In either situation, the patient was transfused with fresh frozen plasma (FFP) and whole blood as required and relatives counseled regarding extending the scope of surgery or need for EBIIAL as an emergency life saving procedure (Fig. 1).

\section{RESULTS}

About $63.3 \%$ patients who underwent internal iliac ligation were young primiparous women who could not have been subjected to obstetric hysterectomy unless there was no other option. The women marry at an early age and $73.3 \%$ of the women were in the age group of 20 to 25 years (Table 1). About $7 \%$ of the women were apparently happy with family size and would not have objected to life saving emergency obstetric hysterectomy, but later on confided that they were

Table 1: Age of women subjected to EBIIAL

\begin{tabular}{lll}
\hline Age groups (years) & Number of patients & Percentage of patients \\
\hline $20-25$ & 22 & 73.3 \\
$25-30$ & 6 & 20 \\
$30+$ & 2 & 6.7 \\
\hline
\end{tabular}

happy to have their uterus with its menstrual function and the option of pregnancy intact. Seventy percent of the cases had some form of predisposing factor like twins, prolonged labor, placenta previa or history suggestive of chorioamnionitis though about $30 \%$ of the cases had no high-risk factor for PPH. Uterine atony was diagnosed easily when the patient was being operated for cesarean section and late diagnosis was the feature of those who had delivered vaginally (Table 2). $93.3 \%$ of the patients received blood transfusion and on an average each patient received 2 bottles of fresh whole blood and 2 bottles of fresh frozen plasma. Anesthetist played a crucial role in managing the fluid balance and pain relief of the patients undergoing crises of $\mathrm{PPH} .93 .3 \%$ of the cases needed blood and or blood products except the two cases where the decision to ligate her internal iliac arteries was taken immediately. It was the anesthetist who was in charge of the asking for blood and blood products after assessing the blood loss (Table 3 ). Fifty percent of the patients underwent internal iliac ligation within an hour of its detection though $13.3 \%$ of the cases were operated upon after 3 hours of managing to control PPH by other means (Table 4). The distance travelled to reach the patient in need of help for ligating internal iliac arteries, on an average was $2.5 \mathrm{~km}$. The distance varied from $0 \mathrm{~km}$ when it was operated in our setup to $25 \mathrm{~km}$ to reach a remote place. In some of the cases the measures to control PPH like uterine massage, administering and repeating the uterotonic agents, trying to ligate the bleeding placental bed, B-Lynch sutures were attempted before making a decision to ligate the internal iliac arteries. Only $13.3 \%$ of the cases $(4 / 30)$ were transferred at tertiary care centers to obstetric intensive care. The transfers were affected for managing early DIC in two patients, for suspected Berger's disease in one and for better postoperative care in the other hospital suspected to have early DIC (Table 5).

\section{CONCLUSION}

The EBIIAL procedure has certainly helped to successfully manage the parturient complicated by PPH at the place of

Table 2: Risk factors for PPH in patients operated for EBIIAL

\begin{tabular}{lll}
\hline Risk factor & Number of parturient & Percentage of parturient \\
\hline None & 9 & 30 \\
Chorioamnionitis/prolonged labor & 7 & 23.3 \\
General infections & 2 & 6.7 \\
Twins/multiple gestations & 2 & 6.7 \\
Induction & 2 & 6.7 \\
Elective LSCS & 2 & 6.7 \\
Pre-eclampsia/HELLP & 2 & 6.7 \\
Placental abruption & 1 & 3.3 \\
History of metroplasty/intrauterine surgery & 1 & 3.3 \\
Precipitate labor & 1 & 3.3 \\
Big baby & 1 & 3.3 \\
\hline
\end{tabular}


Table 3: Blood units and products transfused

\begin{tabular}{lll}
\hline Amount of units transfused & Number of patients & $\begin{array}{l}\text { Percentage } \\
\text { of patients }\end{array}$ \\
\hline No transfusion & 2 & 6.7 \\
$1-5$ & 20 & 66.7 \\
$6-10$ & 7 & 23.3 \\
11 and above & 1 & 3.3 \\
\hline
\end{tabular}

Table 4: Time interval between onset of PPH and EBIIAL

\begin{tabular}{lll}
\hline $\begin{array}{l}\text { Immediate decision } \\
\text { on table }\end{array}$ & 15 & 50 \\
\hline $1-2$ hours & 5 & 16.7 \\
$2-3$ hours & 6 & 20 \\
3 and more & 4 & 13.3 \\
\hline
\end{tabular}

Table 5: Transfer status and reasons for transfer

\begin{tabular}{lll}
\hline Transfer status of patients post EBIIAL & Number of patients & Percentage of patients \\
\hline No. of patients not transferred & 26 & 86.6 \\
Transferred for suspected Berger's disease & 1 & 3.3 \\
Transferred for better postoperative care & 1 & 3.3 \\
Transferred for management of early DIC & 2 & 6.6 \\
\hline
\end{tabular}

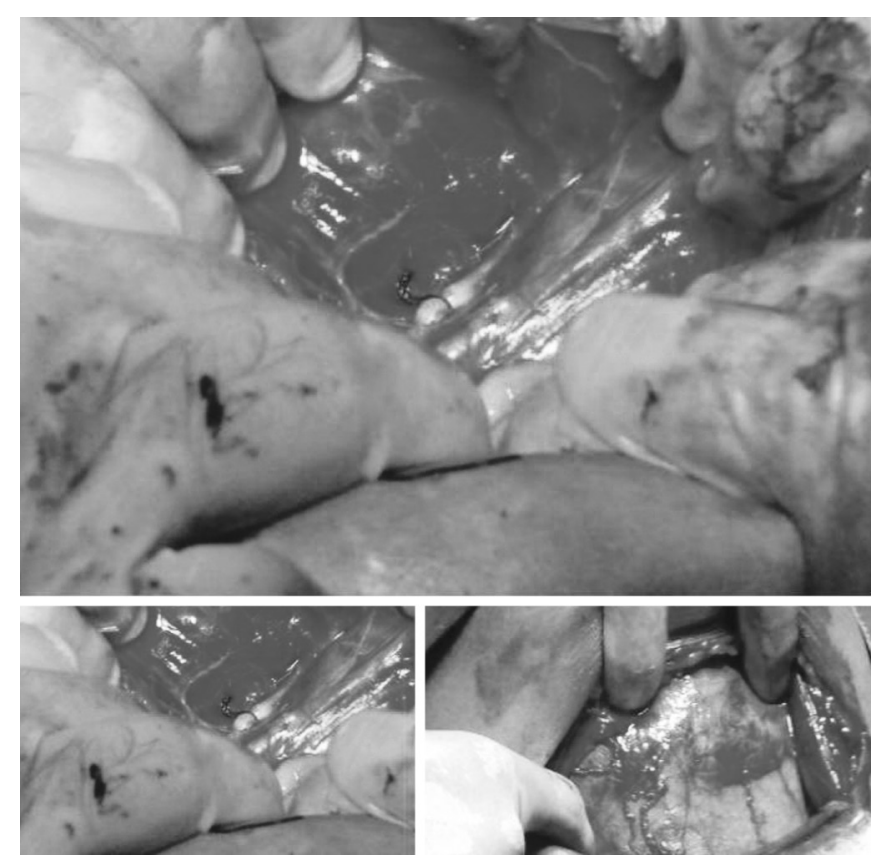

Fig. 1: Exposure of left Internal lliac artery by careful dissection of the retroperitoneal space, taking care to avoid injury to the internal iliac vein

their parturition obviating the need for transferring them for managing PPH. The faster the decision, the lesser the need for blood transfusion and speedier the recovery from surgery with good wound healing (Fig. 2). The outcome of the study can be concluded as under:

1. Bilateral internal iliac ligation can be successfully performed for PPH due to atonic uterus which accounted for majority of the cases in secondary care centers.

2. The use of bilateral internal iliac ligation for managing $\mathrm{PPH}$ at private small and medium sized nursing home reduced the transfers and maternal mortality apart from boosting the confidence of the practicing obstetrician and the community.

3. The preservation of fertility and the menstrual function of the uterus helped to maintain the self esteem and the faith of the patient in the medical practice and helped the

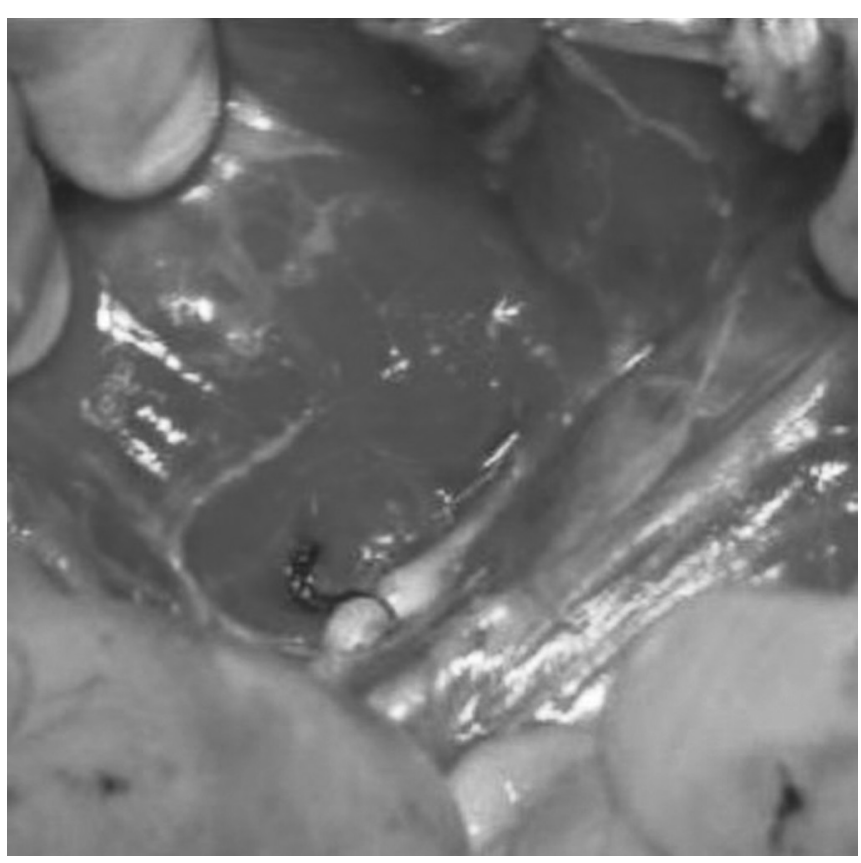

Fig. 2: Close-up view demonstrating the tying of internal iliac artery with nonabsorbable suture material at two places about $1 \mathrm{~cm}$ apart

community to trust the private practitioners in managing pregnancies complicated by $\mathrm{PPH}$.

4. One patient had to subsequently undergo obstetric hysterectomy as her bleeding continued despite bilateral internal iliac ligation and was shifted to tertiary care center for managing early DIC. She was transfused with fresh frozen plasma and fresh whole blood and was discharged after managing the crises from the tertiary care center.

\section{ACKNOWLEDGMENTS}

We are thankful to Ameya Clinic, Panvel, for providing all the logistic support in preparation of this paper and to the obstetricians and intensivists practicing in Panvel and nearby towns to have given us the opportunity to extend our services in managing their cases and handing over the details of those cases. 


\section{REFERENCES}

1. Tajes RV. Ligation of the hypogastric arteries and its complications in resection of the cancer of the rectum. Am J Gastroenterol 1956;26:612-616.

2. Evans $S$, Mcshane $P$. The efficacy of internal iliac artery ligation in obstetric hemorrhage. Surg Gynecol Obstet 1985;1(60): 250-253.

3. Clark SL, Phelan JP, Yeh S-Y, et al. Hypogastric artery ligation for obstetric hemorrhage. Obstet Gynecol 1985;66(3):353356.

4. Mandal D, Mandal S, Maity TK, et al. Role of hypogastric artery ligation in pelvic hemorrhage- is still alive. Al Ameen J Med Sci 2013;6(1):12-16
5. Mathlouthi N, Ben Aved B, Dhouib M, et al. Ligation of internal iliac arteries for severe hemorrhage in obstetric. Tunis Med 2012; 90(3):247-251.

6. Evsen MS, Sak ME, Soydine HE, et al. Internal Iliac artery ligation for severe postpartum hemorrhage. Gynecol Pol 2012; 83(9):665-668.

7. Arulkumaran S, De Cruze B. Surgical management of severe postpartum hemorrhage. Curr Obstet Gynecol 1999 June;9(2): 101-105.

8. Boynukalin FK, Boyar H, Gormus $\mathrm{H}$, et al. Bilateral hypogastric artery ligation in emergency settings for intractable $\mathrm{PPH}$ : a secondary care center experience. Clin Exp Obstet Gynecol 2013; 40(1):85-88. 